\title{
Research on the Spatial Distribution Characteristics of $b$-value in Southwest Yunnan
}

\author{
XIE ZHUOJUAN1, a, LU YUEJUN1, b \\ 1Institute of Crustal Dynamics, China Earthquake \\ Administration,Beijing,100085 China \\ aemail:3377242@qq.com,bemail:luy1@263.net
}

\begin{abstract}
Southwestern YUNNAN is located in the southeast edge of the Tibetan plateau, is one of strong continental tectonic activities and frequent earthquake area in our country. In this paper, spatial difference of distribution b values along the fault belt, reflect the level of stress accumulation and activity habits in the different fault belt and the same fault different section, which reflects the spatial difference of seismic risk. The research result shows that the distribution $b$ value and different sections in the Fault belt and fracture belt are uneven. The researching methods of this article and its conclusion can be used as seismic activity and risk evaluation research reference in the same area. The study results have important value for seismic risk zone and seismic safety assessment.
\end{abstract}

Keywords: southwestern YUNNAN, spatial distribution of b values

\section{Introduction}

Located in the southeast edge of the Tibet Plateau, Southwest Yunnan is adjacent to Sichuan-Yunnan rhombic block phase on the east and northeast of the Indian plate tentacles on the northwest. Southwest Yunnan is one of the earthquake-prone regions in our country [1] [2]. Because the region is affected by multiple sets of fault, there are intense seismic activities. However, several major fault zones have been quiet for 20 years since 1988, the formers have done researches on the seismic activity and future seismic trends in this region by different approaches [3] [4] [5]. But their researches didn't fully reflect the seismic activity characteristics, and unable to carry out researches on the activity features of several main fault zones and potential earthquake risk zones. Therefore, Southwest Yunnan is selected for the study in this paper, by using spatial distribution differences of $b$-value along the fault zone space of Southwest Yunnan, different fault current differences are reflected in the same fault zone as well as various stress accumulation and activity habits; therefore spatial difference of seismic hazard is reflected. Research methods and conclusions of this paper are available to be used as the reference for analyzing seismic activities, and they are important for seismic zoning, engineering and 
seismic safety evaluation, and long-term forecasting of seismic activities.

\section{Profiles of regional seismic tectonic background and seismic information}

Located in southwest Yunnan Plateau, Southwest Yunnan is composed of high plateau and mountains with altitude from 1000 to 3000 meters s. The region has experienced several tectonic movements, and the new tectonic movements are very strong, with well-developed faults. Three groups of north-west, north-east and north-south faults in the region are crossed, Northwest trending fault rupture areas are represented by the Red River fault, mainly distributed in the northeast of Southwest Yunnan plots; Northeast trending fault rupture areas are mainly located in the west of the Lancang River, with relatively small fracture scale and extended in parallel equidistant distribution, unable to continue extending northward and eastward basically blocked by the Lancang fracture; North-south trending faults are represented by the Nujiang fault zone, and are located in the northwest of Southwest Yunnan plots, with large scale and strong activities, controlling the formation of Tengchong's northward basins[6].

Earthquakes recorded in the region are 28,192 since AD 886, with seismic intensity $1.0 \leq \mathrm{M} \leq 7.4$ level, in which 15260 times from 1.0 to $2.0,9557$ times from 2.0 to 2.9, 2849 times from 3.0 to $3.9,361$ times from 4.0 to $4.9,139$ times from 5.0 to $5.9,14$ times from 6.0 to $6.9,12$ times from 7.0 to 7.9 . 


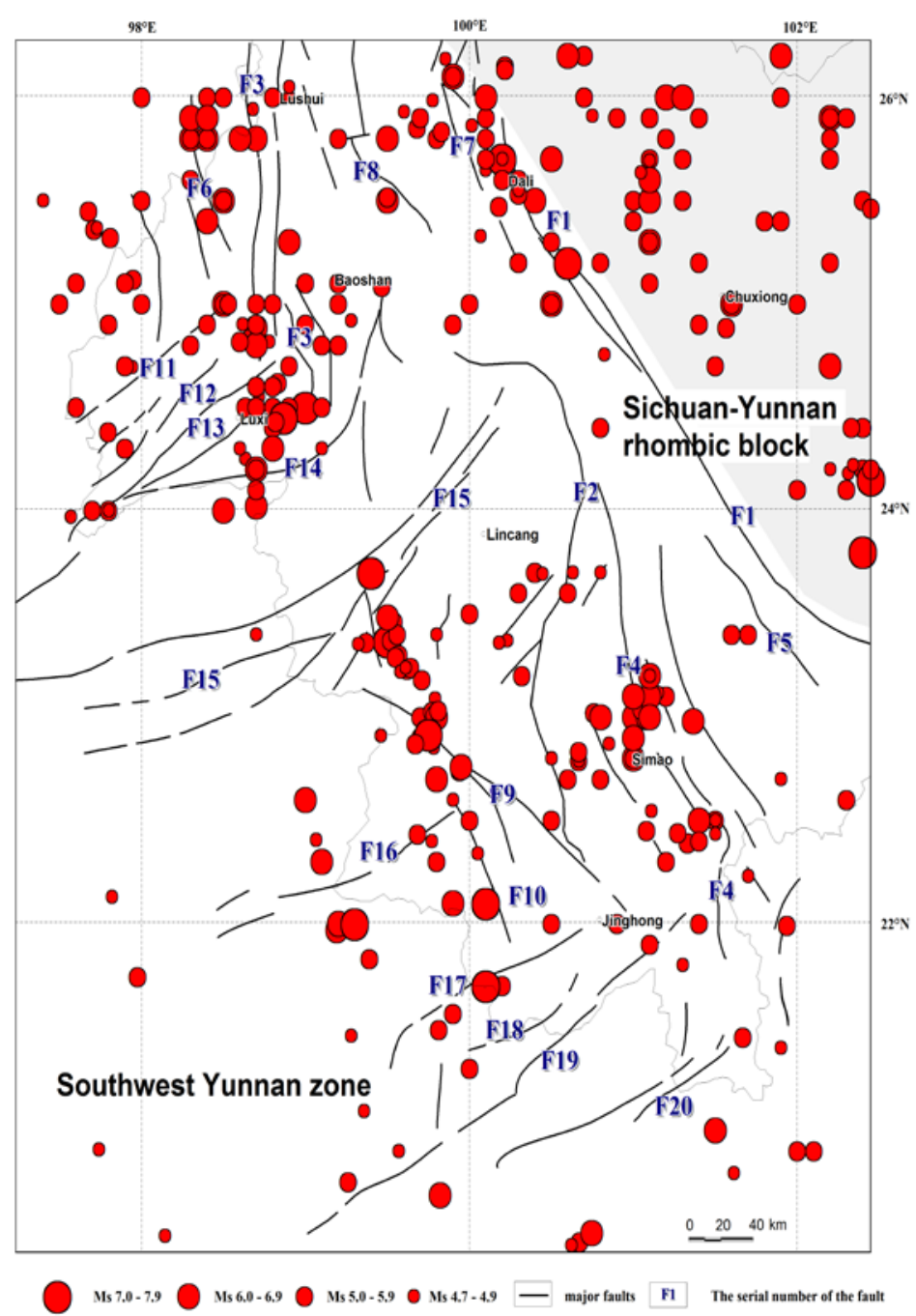

Fig.1 Distribution of regional historical strong earthquakes and major faults It can be seen by combining with regional tectonic setting and historical earthquakes distribution: the regional big earthquakes are distributed extremely uneven in the history. Affected by multiple sets of faults, there are intense seismic activities, their overall performance is high intensity and frequency, with clear characteristics of plate edge earthquake and interpolate earthquake.

\section{Spatial distribution characteristics of $b$-value}

\section{Method}

Methods for calculating b-value of seismic activity mainly are the least 
squares and the maximum likelihood method. In 1980, Yu-chun Dezhi proposed the formula to calculate the b-value by using the maximum likelihood method in the study of magnitude - frequency relationship parameters:

$$
b=\frac{0.4343 N}{\sum_{i=1}^{N}\left(M_{i}-M\right)}
$$

In the formula (1), $\mathrm{N}$ is the total number of earthquake samples; $\mathrm{M}_{0}$ is the initial earthquake magnitude; $M_{i}$ is for each earthquake's magnitude, where $M=$ $\mathrm{M}_{0}-0.05$. According to the results of Shi etc [7], the standard deviation value $\delta \mathrm{b}$ of $b$ is:

$$
\delta b=2.3 b^{2} \sqrt{\frac{\sum\left(M_{i}-\bar{M}\right)^{2}}{n(n-1)}}
$$

Viewed from the formula (2), the maximum likelihood method uses the same weights for averaging all earthquake magnitudes, which equals to weight a large number of small earthquakes' information [8]. Because a large number of small modern seismic data is used in this study, so the maximum likelihood method is used to calculate the spatial distribution of the regional b-value, and b-value calculated results are given with a confidence level of $90 \%$.

\section{Spatial scan of b-value}

Southwest Yunnan is in long block shape, thus it is not suitable to use a circular area with a larger radius as a sliding window to scan and calculate. This study uses a grid form to do spatial scan, and divides spatial interval grid in $0.02^{\circ} \times 0.02^{\circ}$. Seismic data is picked out within the circular statistics units, taking each grid center as the circle center and the radius being $\mathrm{r}$ ( $\mathrm{r}$ value is $40 \mathrm{~km}$, so as to ensure enough samples). It is ensured that an average of 100 earthquakes are involved in the circle calculated unit (less than 40 seismic grids do not participate in the calculation, and they are shown in blank area) . Finally, the study area is scanned and calculated b-values of all grid points, interpolation is used to interpolate discrete points, draw contour, and forms the spatial distribution image of b-value.

Figure 2 is b-value spatial distribution and the main fracture distribution of the obtained study area, it can be seen the b-value of Southwest Yunnan is extremely uneven in its spatial distribution, seismic data in the southwest corner and Jingdong Yi Autonomous County area is too small, so b-value spatial distribution image is displayed as a blank area. b-value of Jinghong, Mengla, Simao, Tengchong etc is relatively low, so that there is the possibility of earthquake; b-value of Yongren, Mo River, Red River and several other local areas is higher than 0.9 , which shows that lots of these faults have little creep properties of frequent seismic activities, the possibility of future strong earthquakes is relatively small. The average b-value in the study area is $0.576 \pm 0.046$. 


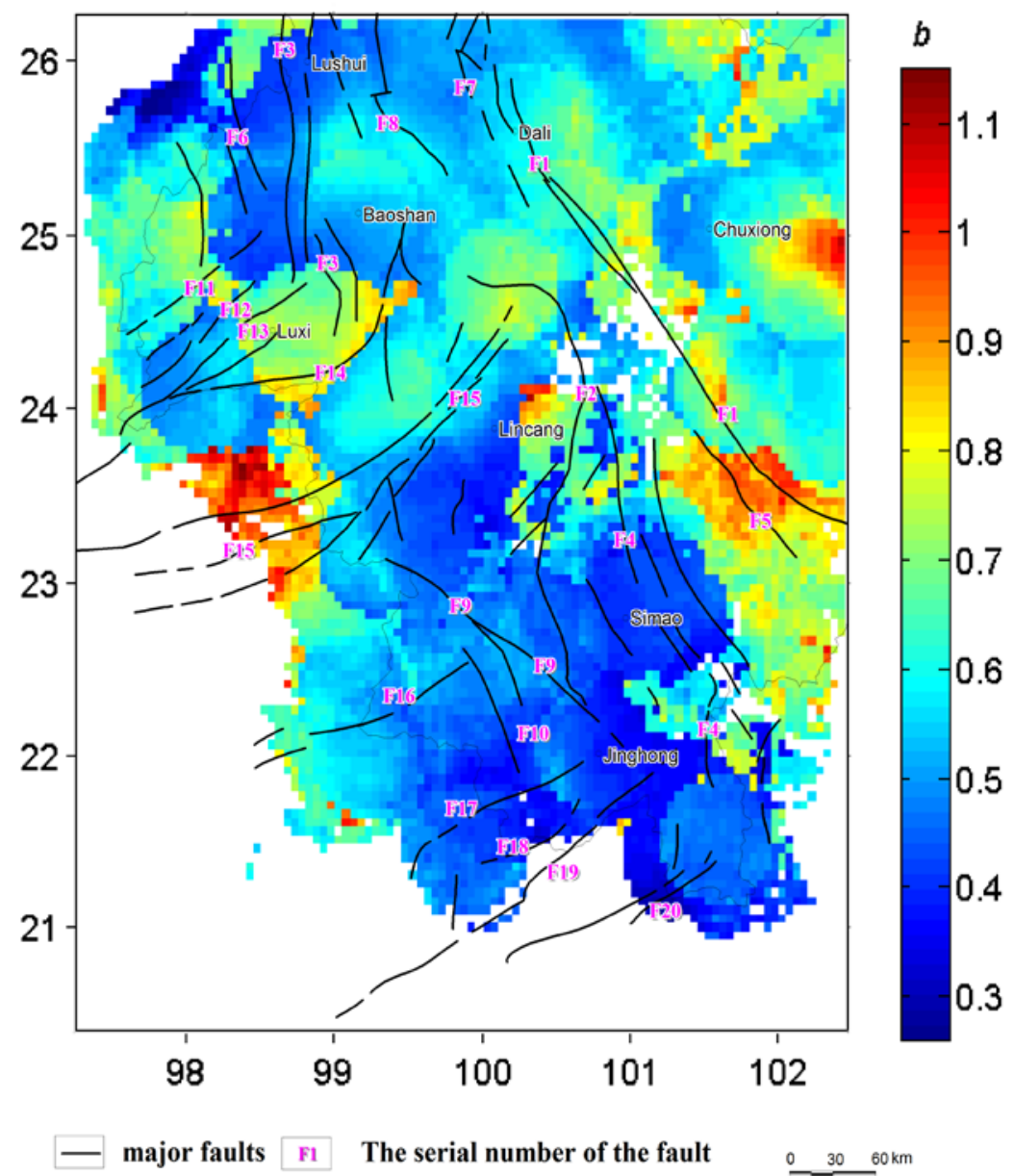

Fig.2 $b$-value spatial distribution of the study area and the main faults distribution

\section{Conclusion}

The following conclusions and understanding are obtained through this study: Southwest Yunnan is affected by multiple sets of faults, so that there are strong seismic activities, b-value of different sections of faults is distributed uneven. Northern section of the Honghe fault(F1), southern section of the Lancang fracture(F2), Nujiang fault(F3), east branch of the Wuliangshan fault(F4), west branch of the Tengchong Quaternary volcanic fault line(F6), the middle section of the Longling - Ruili fault zone(F13) is in the low b-value area, and is in a relatively higher stress state currently, the possibility of a strong earthquake is high in the next few years. While the Ailaoshan fault, the Longling - Ruili western par, the eastern section of the fault zone, the Wanding - stable fracture 
and west branch of the Nanting River fault are in the high b-value area, is at a relatively low level of stress accumulation at present, the small earthquakes may occur in the future.

\section{Acknowledgement}

In this paper, the research was sponsored by the Institute of Crustal Dynamics, China Earthquake Administration (Project No. ZDJ2013-05).

\section{References}

[1]XIE Fu-ren,SU Gang,CUI Xiao-feng,et al. Modern tectonic stress field in southweatern YUNNAN,CHINA[J].Acta seismologica sinica, 2001,23(1):17-23(in Chinese).

[2]CHEN Li-de. On March 15, 1979 YUNAN PUER earthquake of magnitude 6.8 [A].C.E.A. China earthquake cases [C].BeiJing: Earthquake Publish Company: 1990,302-326.

[3]FU Hong,WANG Shi-qin, QIN Jia-zheng, et al. Medium-term,Short-term and Impending-earthquake anomaly Characteristics and Prediction of the $\mathrm{M} \geq 5$ Grouping earthquakes in Southwest Yunnan during May-June 2007[J].Journal of seismological research, 2007, 30(4)303-310(in Chinese).

[4]SHI Shao-xian, FU Hong.Preliminary research on next strong earthquake active period of LANCANG,GENGMA earthquake belt[J].Inland earthquake, 2009,23(4):417-423(in Chinese).

[5]BI Qing, SHENG Kun, XU Wai-fen, et al. Analysis of seismic characteristics in southwest of YUNNAN[J].Plateau earthquake research, 2010,22(1):10-16(in Chinese).

[6]Institute of Geology, C.E.A. The report on the seismic tectonic environment of Chinese mainland and adjacent regions[R].Beijing. 2009.

[7]Shi Y,Bolt B A. The standard error of the magnitude-frequency b value[J].Bulletin of the Seismological Society of America, 1982,72( 5) : 1677-1687.

[8]WANG Hui,CAO Jian-ling,JING Yan, et al. Spatiotemporal pattern of b-value before major earthquakes in the Sichuan-YUNNAN region[J]. Seismology and Geology, 2012, 34(3):531-543(in Chinese). 